\title{
Assessing the Integrative Framework for the Implementation of Change in Nursing Practice: Comparative Case Studies in French Hospitals
}

Israa SALMA ( $\sim$ israa.salma@eleve.ehesp.fr)

EHESP https://orcid.org/0000-0003-3478-044X

Mathias WAELLI

École des Hautes Etudes en Santé Publique: Ecole des Hautes Etudes en Sante Publique

\section{Research}

Keywords: implementation, Integrative Framework for Implementation of change in Nursing Practices, strategic level, socio-material factors, interferences, mechanisms of mobilization, leadership, local managers.

Posted Date: November 22nd, 2021

DOI: https://doi.org/10.21203/rs.3.rs-1068022/v1

License: (c) (i) This work is licensed under a Creative Commons Attribution 4.0 International License. Read Full License

Version of Record: A version of this preprint was published at Healthcare on February 23rd, 2022. See the published version at https://doi.org/10.3390/healthcare10030417. 


\section{Abstract \\ Background}

Quality improvement initiatives in healthcare often require change in nursing practices. Implementing such change into routine practice is challenging, often with unpredictable outcomes. Extensive research in this area has documented effective implementation change in clinical practice and identified barriers and facilitators at strategic levels, e.g. leadership, culture, and technical factors, which are common across most organizations. However, other research avenues have investigated different perspectives, e.g., the impact of local work contexts on implementation processes and the overlap of local social and material factors in appropriation processes. Therefore, considering both perspectives is essential for effective implementation. However, strategic and socio-material factors have only been investigated as distinct perspectives. In previous work, we developed an Integrative Framework for Implementation of change in Nursing Practices (IFINP) based on certification procedure implementation at a French hospital. In this current study, we assess the generalizability of our framework in other organizational settings and explore links between strategic and socio-material factors during implementation.

\section{Methods}

We used comparative qualitative case studies at three French hospitals to assess the implementation of certification procedures. Data were collected from 33 semi-structured interviews with managers and nurses. Narratives reflecting actions and interactions were extracted and deductively analyzed using IFINP components.

\section{Results}

The framework was flexible and captured all the different aspects of implementation actions and interactions at the three hospitals. Strong interferences were identified between mobilization mechanisms and strategic elements. Interference was observed mostly between 'reflexive monitoring and work articulation', and 'reflexive monitoring and sense-making' mechanisms. Leadership was integrated into the different mechanisms, especially the 'translation' mechanism.

\section{Conclusion}

The IFINP facilitated a greater understanding of strategic elements and associated relationships with social and material factors during implementation. Our results support the non-linearity aspect of implementation processes and highlight the importance of leadership roles in translating change in practice. This provides a clear definition of the managers' role when implementing new nurse practices. 
Therefore, we advocate the IFINP as a practical managerial framework supporting implementation initiatives in nursing.

\section{Contribution To The Literature}

- This study shows how the Integrative Framework for Implementation in Nursing Practice (IFINP) considers both strategic approaches and activity levels during implementation processes.

- IFINP is flexible and captures multiple interactive factors in different contextual settings for certification implementation procedures.

- Multiple interferences exist between strategic level elements, such as leadership approaches and mobilization mechanisms. Also, intra-interferences exist between mobilization mechanisms during implementation processes.

- This study addresses knowledge gaps in the literature relating to the role of local social material factors in an implementation context.

\section{Introduction}

Quality improvement (QI) initiatives are increasingly adopted in healthcare organizations to improve patient care quality [1,2]. They exert a considerable impact on nurses' work [3] in terms of increased requirements and regulations during professional practice [2]. The effective implementation of a QI initiative is associated with positive patient and staff outcomes and enhances care cost-effectiveness [4]. However, the failure of such implementation may have a serious impact, causing additional workloads and increased staff burden [5]. Previous research reported that anxiety toward integrating innovations in practice is a common concern [6]. Implementing such changes into routine practice is challenging and its outcomes are unpredictable and uncertain [7]. As a consequence, researchers have investigated how to effectively implement change into clinical practice [8] by identifying factors may impact implementation processes, and using models, theories, and frameworks [7, 9].

Implementation as a subject has been investigated from two different perspectives. The first draws primarily on a strategic approach and identifies a wide range of transversal factors and implementation strategies applicable to multiple clinical settings, including leadership, culture, resources, and others [10, 11]. Similarly, multiple frameworks, models and theories have been developed [12, 13], including Promoting Action on Research Implementation in Health Services and the Consolidated Framework for Implementation Research [14, 15].

The second perspective is centered on activity levels and focuses on local socio-material contexts and the impact on implementation processes [16, 17]. Additionally, these perspectives focus on a clinical manager's role to generate quality improvements/results [18]. Andreasson et al. speaks of a potential risk of failure in implementing such changes in care processes by top management given the existing gaps between strategic and operational levels in hospitals [19]. Previous research reported that bridging such gaps between strategic and activity levels primarily depends on clinical managers translating and 
adapting intended changes to local contexts $[18,20]$. As outlined in the theory of middle management roles, "a middle managers commitment to innovation implementation is operationalized over four steps: 1) obtaining and communicating information about an innovation; 2 ) adapting information and the innovation; 3) mediating between strategy and day-to-day activities; and 4) selling innovation implementation" [21].

Facilitator factors related to work settings at strategic levels [22] and the dynamic aspects of local contexts, and how they interrelate during an implementation process, are both essential steps towards an effective implementation at the activity level [23]. However, these factors are generally, separately addressed. Thus, it is important to address both steps in an integrative framework to identify strategic levels, consider specificity, and analyze the local context of implementation. For example, how is leadership operationalized in an implementation process, given its complexity and the overlapping reality of the local context. Within these perspectives, we previously developed a framework for innovation implementation at nurses' levels, i.e., the Integrative Framework for Implementation in Nursing Practice (IFINP) [24]. The framework was developed using a two-step mixed approach. The first was an inductive analysis of the certification implementation procedure at a teaching hospital. The second was a deductive analysis using two theoretical approaches: the Quality Implementation Tool (QIT) [25] and translational mobilization theory (TMT) [26].

While multiple implementation frameworks have been developed, limited studies have evaluated the usefulness of these promising approaches [12]. In this study, we first tested the IFINP using certification implementation procedures as an example in multiple case study settings (three French hospitals). Our strategy was to identify how framework components captured implementation processes in multiple organizational settings. Secondly, we explored the links between strategic elements and socio-material factors of the implementation process in a local context.

\section{Methodology}

\section{Choice of certification procedures}

The implementation of certification procedures was used as the subject to test the IFINP. First, a certification is considered as one of the main "peer evaluation techniques" in Europe, which is based on the International Organization for Standardization. In France, a certification is mandatory in both public and private health organizations[27]. And thus it was useful to study implementation processes in different organization types. Second, the evaluation strategies of certification are based on standards and benchmarking, and must, given this, include the best clinical practices, processes audits and associated to quality and safety indicators [27]. These regulations to manage and improve care quality define the scope of actions for health organizations' quality program. Accordingly, each hospital defines an action plan listing the objectives, intended actions and practices changes to implement, and responding to certification perspectives. Implemented practices could include a new practice guidelines, required technologies or materials, protocol changes and others... [24]. The implementation of 
certification is a key managerial issue, in terms of the preparations, its implementation, and sustainability in professional routine practice [28]. Especially, where it is perceived, given the multiple requirements, increasing workload for professionals [2], many primarily nurses [3]. However, the requirements are essential for improving care quality and patient safety [29]. Thus, it was important to assess framework utility in understanding the implementation processes of certification implementation procedures in multiple organizational settings.

\section{Study design}

We used a comparative qualitative case study approach. A case study examines phenomena in 'real life' contexts [30], e.g., understanding the implementation of an intervention in a healthcare system [31]. This approach explores phenomena from different perspectives; "Through case-by-case comparisons, the analyst fine-tunes, modifies, and qualifies the propositions so that they express precisely the limiting conditions revealed by the pattern of findings across all cases" [32].

\section{Study locations}

We selected two hospitals in western France, distinguished by size, type, and status. IFINP had previously been developed by us in high risk sectors at a teaching hospital center (hospital A) [24]. To broaden our remit, we investigated other sector types in hospital $A$, and also other hospitals types (B and $C$ ) (Table 1).

\section{Data collection}

Data was collected using semi-structured interviews with relevant actors involved in certification implementation procedures. Due to the ongoing COVID-19 pandemic and associated restrictions, we were unable to conduct observations at study sites.

\section{Interviews}

As multiple actors at different organizational levels were involved in certification procedures, interviews were conducted with actors at different hierarchies. This approach provided in-depth insights on the role and responsibilities of actors at each local context and provided a better understanding of the different factors impacting the process [33]. Interviews were conducted until 'data-saturation'; interviews were conducted until outputs provided non-essential data related to study objectives [34]. To avoid bias related to a directed enquiries on framework components, interviews were conducted in a comprehensive manner; we discussed the implementation of certification procedures and processes at nurse activity levels. Also, we elaborated on elements contributing to successful change integration processes imposed by these procedures on nurse practices. Interviews were conducted by the PI (IS), either face-to-face or online, according to hospital regulations and participant preference. The participants and their roles at each site are listed (Table 2).

In total, 33 semi-structured interviews were conducted at the three sites. To ensure participant anonymity, interviews were sequentially numbered in each site, using acronyms based on participant roles: TL; top 
leader, $\mathrm{MM}$; mid-manager, and $\mathrm{RN}$; registered nurse. $\mathrm{A}, \mathrm{B}$, and $\mathrm{C}$ denoted the site. For example, the top leader 1 at site $B$ is TL1-B, register nurse 5 at site $C$ is RN5-C

\section{Data analysis}

\section{The theoretical framework}

The IFINP framework was developed to conceptualize innovation implementation at nursing activity levels in French hospitals (Fig. 1). The framework distinguished two key components in implementation certification procedures. Firstly, contextual settings were considered as strategic elements, e.g., actors, organizational logistics, structures, materials, technologies, interpretative repertoires, and implementation leadership approaches [35]. Secondly, mobilization mechanisms encompassed actions, practices, and interactions between these elements. The framework incorporated five mechanisms: 1) object formation,

2) translation, 3) sense-making, 4) reflexive monitoring, and 5) work articulation (Table 3). These shaped and guided implementation processes, thereby reflecting local socio-material factors [24]. The framework also showed how an implementation context consisted of both social and material elements interacting together in a continuum, rather than a linear 'pipeline' approach [36].

\section{Data coding}

All narratives reflecting implementation processes, such as actions, interactions, key factors, contextual settings, and others were stored in separate computer files with respect to each hospital. Narratives were then used in a deductive analysis using framework elements in a table format (Table 3). To ensure analytical credibility, both authors conducted a simple test to characterize categories and define inclusion and exclusion criteria; authors separately conducted coding for a sample of narratives $(n=30)$ according to definitions (Table 3). Then a discussion followed on the primary results of coded sample narratives. This process helped frame each category and define inclusion and exclusion criteria. Then, the principal investigator (IS) performed narrative coding steps. Study reporting guidelines were based on consolidated criteria for reporting qualitative research (COREQ) (Additional file 1) [37].

\section{Research ethics}

This study involved professionals and no patients or human experiments. In France, this type of study does not require institutional review board (IRB) authorization as is the case in the United States [39]. In France, according to "Jarde law" L1121-1 PHC, three study types involving humans require ethical approval: 1) human interventional studies, 2) studies with minimal risk and intervention, 3) and noninterventional studies (in the context of patient data) [40]. According to qualitative research ethics guidelines [41], signed consent from participants is adequate, and interviews should be conducted in private, comfortable, and informal settings. In this study, participants were free to participate. Also, to maintain strict anonymity, interviewees and interview transcripts were anonymized and assigned acronyms. 


\section{Results}

Firstly, all interviewee narratives reflecting actions and elements in certification implementation procedures were captured by the framework (Table 4). IFINP categories described emergent issues at all sites (Cases A, B, and C) and sectors in the same hospital, whether general medicine, ICU, and interventional sectors (endoscopy and the operating room). Thus, the framework recognized the mobilized implementation elements, actions and interactions for the implementation of certification procedures into routine practice.

Secondly, we identified overlapping aspects with respect to framework elements. Multiple narratives showed an interference between two or more mobilization mechanisms and also between strategic elements and mobilization mechanisms (Additional file 2). Interference is understood as an overlap or an intrusion of two or more elements during a process. In this study we used 'interference' to describe the overlaps identified in certification implementation procedures. Interview analyses showed that overlaps were mostly observed between both 'reflexive monitoring and work articulation' and 'reflexive monitoring and sense making' mechanisms at the three sites. However, the 'object formation' mechanism was only weakly associated with the 'translation' mechanism when compared with the other mechanisms. Some narratives reflected associations between multiple mechanisms, and sometimes with contextual elements. For example, "we use quality meetings to explain certification procedures to managers and professionals. We work with the quality unit who provide regular updates on different indicators and outcomes. Also, our auditing systems help us monitor the integration of new procedures into routine practice" TL1-C reflecting shifts between 'translation', 'reflexive monitoring', and 'work-articulation'. In another example; "for implementation procedures, we identify referents/champions, we improve their skills and train them in methods and tools required for certification, quality and risk management, so they can introduce/implement change and help nurses to change" TL2-B. This statement reflected the leadership of the referent/champion through 'reflexive monitoring' and 'work articulation' mechanisms. In this study, 'referent' is a key actor in the implementation process and is considered a champion; the term refers to their role as reported by Salma and Waelli, 2021 [24]. In addition, leadership was associated with each mechanism, but strongly interfered with the 'translation' mechanism. We identified two leadership levels. The higher level generally interfered with 'object formation' mechanisms; "we are supported by the quality unit of our hospital in implementing quality policies; their help defines the working plan at different levels" MM2-A. The leadership proximity manager and/or the leader of change at the professional level states, "we provide necessary training for nurses and we consider different contextual settings in which to implement new practice changes, such as working procedures and essential documents, so when we introduce change we have everything in place" MM2-B. Given the dynamic aspect of an implementation context, it is important to consider the local socio-material impact as well as barriers and facilitators that may impact implementation processes. This operationalizes strategic elements such as leadership within a local context and shows how they are interrelated (Fig. 2).

The following sections outline stratified comparisons between the three case studies based on interferences identified between mobilization mechanisms and leadership. 


\section{Comparison of 'object formation' and 'translation' mechanisms and interferences with leadership}

'Object formation' reflects the initial mobilization step of certification procedures within an organization. We identified similar practices for this initial step across the three sites (Table 5). Generally, the TL, MM, specialists, and a steering committee enacted action plans based on certification criteria and departmental evaluations. This plan defined the objectives and actions for each department. All information regarding procedures or actions was communicated by managers or informatics systems. At the nurse level, referents/champions or local managers were charged with communicating procedures and changes, either during meetings, e-mail and/or circulated documentation. In essence, they prepared the local context to accept change. 'Object formation' was accompanied by 'translation' mechanisms. The introduction of any procedure must be defined in terms of needs and requirements. For example, at the organizational level, this was done by explaining 'why' and 'how' a procedure was to be introduced and integrated at each level. At the local professional level, this was justified as a procedural need and benefit for patient care and depended on the leadership skills of proximity managers to use formal and informal strategies to support and provide meaning to the implemented change.

\section{Comparison of 'sense-making', 'reflexive monitoring', and 'work articulation' mechanisms with the leadership}

Communicating information and explaining procedures does not guarantee an effective implementation; it must also make sense for professionals; "we can write a procedure, we can explain it, and we can introduce it to nurses, but the most important thing is that this procedure is effectively implemented in their daily practice" MM2-A. We identified multiple managerial strategies to make sense of implemented procedures in nurse practices (Table 6). Primarily, managers insisted on involving nurses in these procedures, often at inception. Nurses were actively engaged in the development and writing of procedures (sites $A$ and $B$ ). This also involved organizing interventions, giving feedback and opinions on procedures and changes (site $\mathrm{C}$ ). Local managers also provided administrative support for professionals using informatics systems or documentation. These steps were essential for working procedures and policies. This was identified as tool supporting professionals' practices. In addition, to effectively implement a procedure, interviewees highlighted the usefulness of a pilot period which allowed professionals to live and experience the change, readjust and adapt according to local context reality, and unlimitedly accept it and use it.

We observed similarities in 'monitoring' and evaluation methods across the three sites (Table 6). 'Reflexive monitoring' was represented by 'formal' tools such as auditing systems, indicators, professional practice evaluations, and adverse events. Also 'informal' methods were facilitated through professional's feedback on procedural feasibility, which relied heavily on the local leadership. Nurse's provided feedback either directly to local managers and referents or at regular team meetings. This helped evaluate procedures and air concerns. The 'reflexive monitoring' mechanism interfered not only with 'sensemaking' mechanisms but also with 'work articulation' mechanisms. Continuous monitoring was fundamental to ensuring corrective actions and improved procedural integration. These continuous 
improvements are incorporated in work articulation mechanisms. The ability to conduct continuous and regular meetings and ensure communications between actors at multiple organizational levels allowed actors to readjust, adapt, and formalize change trajectories.

\section{Discussion}

We tested our IFINP framework for the implementation of certification procedure using comparative case studies in three French hospitals.

Firstly, we demonstrated framework flexibility in capturing the reality of certification procedure implementation in multiples settings in different French healthcare organizations. The IFINP successfully identified different actions and interactions between actors, contexts, and implemented procedures, regardless of sector type, hospital type, and size. Although the framework was originally constructed using a case study in high risk sectors at a teaching hospital [24], it was practical for explaining certification procedures in other sectors (medicine; case A), and other hospital types (cases B and C). This provided a formal framework to understand mechanisms where individual and organizational contexts affected innovation integration into nursing practice [12].

Secondly, we revealed a strong interference on framework elements during implementation processes. Repeatedly, participant narratives reflected an interposition between different mobilization mechanisms during certification implementation across the three sites. But mostly, interferences were identified between 'object formation' and 'translation' mechanisms at higher manager levels, and 'sense-making', 'reflexive monitoring', and 'work-articulation' mechanisms at activity levels. This may be explained by the presence of two implementation phases. The first phase reflected the adoption of certification procedures at the organizational level and involved actions related to the preparation of the initial mobilization and change diffusion, and was mostly seen at higher levels. For example, through regular teams meetings, leaders defined the organizations' plan with other actors, they explained and translated certification criteria in daily practice.

The second phase reflected the appropriation of implemented change by professionals into their routine practice. This involved different actions by local mangers or change leaders, leading to the effective integration of change. For example, professional involvement in procedures responded to 'sense-making' mechanisms and was observed by an active engagement via analyses and evaluations. Also, feedback and improvement suggestions interfered with the 'reflexive monitoring' mechanism. Also, through 'reflexive monitoring' e.g. monitoring meetings, managers and professionals defined corrective actions. They continuously evaluated, adapted, and readjusted implemented procedures according to local context requirements and interfered with the 'work articulation' mechanism. Healthcare system complexity [42] is accompanied by implementation procedural complexity - via multiple contributors and multifaceted and multidimensional strategies [43]. This situation requires a dynamic constituent to improve the uptake of important changes by professionals [44]. Thus, identifying interferences in IFINP 
mobilization mechanisms and elements during certification implementation procedures is important and supports the non-linearity aspect of implementation processes [17].

In addition, the IFINP helped exemplify the leadership factor. Leadership interference with different mobilization mechanisms was useful in defining the content and activity undertaken by change leaders and their response to mobilization mechanisms. For example, leadership at the organizational level involved top leaders providing information and clear instructions on adopted changes. They also supported managers and professionals at regular meetings $[45,46]$. This situation reflected an interference of leadership in terms of 'object formation' and 'translation' mechanisms. In addition, leadership approaches [47] at the local level interfered with translation, sense-making, reflexive monitoring, and work articulation mechanisms. This scenario provided important insights on the change leaders' role in translating and adapting procedures to the local context, and thus integrating them into professional practice. These outputs also highlighted their willingness to implement certification procedures at the three sites. From this, a question arose on the place of local managers' roles and activities which must be considered by decision-makers in implementing quality policies [18]. Using the IFINP, we showed that the leadership approach involved considerable translation, support, and monitoring changes, whereas, other strategic approaches emphasized the leadership as facilitators, without clear conceptualization $[48,49]$. Thus, the IFINP helped frame these elements within the local implementation context.

Thirdly, the stratified comparisons of IFINP elements based on overlaps, revealed major similarities between implementation strategies and interventions across different sector types (case $A$ ) and hospitals (cases $B$ and $C$ ). This suggested independent certification implementation strategies at the three sites. This could be explained as the generation of work harmonization and standardization processes between French healthcare organizations in terms of quality management [50]. To address this, we advocate the study of international contexts and other types of managerial innovation.

\section{Study limitations}

We acknowledge several study limitations. Our cases focused on the implementation of certification procedures at the nurse level, thus participants at the activity level were nurses. However, the implementation scope was broad and certification procedures involved many professionals, not only nurses. Thus, we may have missed data on some implementation processes. Secondly, in terms of our data collection methods, the study was primarily based on semi-structured interviews. However, given the COVID-19 crisis and associated hospital restrictions, we were unable to conduct observations at sites which may have limited some study elements. However, to overcome this, we thoroughly discussed certification implementation procedures with actors, and sought examples from their previous experiences. Finally, we tested the framework in multiple hospital settings, but based on the last iteration of certification and not during the implementation process of certification. However, in the future, it will be interesting to test IFINP utility in real-time certification procedures. 


\section{Conclusions}

Using comparative cases studies we assessed the IFINP. The framework robustly provided insights on existing interferences between framework components, mechanisms and elements, and practically explained certification implementation procedures in multiple contexts. The IFINP provided concrete and explicit insights on the leadership in terms of a change leader's activity on the implementation process. Therefore, we advocate IFINP in supporting implementation initiatives in nursing practices, regardless of the organization type. The IFINP identifies key elements in these processes and potential interference elements in local socio-material contexts.

\section{Abbreviations}

Ql: Quality improvement

IFINP: Integrative Framework for Implementation of change in Nursing Practices (IFINP)

ICU: intensive care unit

CLIN: comité de lutte contre les infections nosocomiales (nosocomial infection control committee)

CLUD: comité de lutte contre la douleur (committee for pain relief and control)

\section{Declarations}

\section{Ethical approval and consent to participate}

This study involved professionals and activity analyses, with no patient involvement or human experiments. In France, this study type does not require ethical approval. The study was conducted in accordance with ethics in qualitative research guidelines. All participants provided oral confirmation and written informed consent before participating.

\section{Consent for publication}

This included consent to publish anonymous quotes from participants.

\section{Availability of data and materials}

Datasets (which include individual transcripts) are not publicly available due to confidentiality policies. However, they may be obtained from the corresponding author upon reasonable request.

\section{Acknowledgments}

The authors acknowledge Dr. John P. Phelan for editing and proofreading the manuscript.

\section{Funding}


This study was funded by Bebnine Municipality. The funder had no role in the study - neither in the writing of the manuscript nor in the decision to submit for publication.

\section{Competing interests}

The authors declare no competing interests.

\section{Author contributions}

IS and MW conceived the idea. IS, with the help of MW designed the study. IS was PI and performed observations, interviews, analyses, and developed the conceptual framework. IS wrote the first draft and collaborated with MW to generate the final draft. MW verified the analytical methods, proposed corrections, and supervised the overall research. Both authors provided critical feedback and helped shape the research, analyses, and final manuscript. Both approved the final version.

\section{Author information}

IS is a doctoral student at the School of Public Health EHESP, Rennes, France. MW is associate professor at MOS-EHESP, Paris/Rennes, France and lecturer at the Global Health Institute, Geneva University, Geneva, Switzerland.

\section{References}

1. Jeffs LP, Lo J, Beswick S, Campbell H. Implementing an organization-wide quality improvement initiative: insights from project leads, managers, and frontline nurses. Nurs Adm Q. 2013; 37(3):22230 .

2. Allen D. Care trajectory management: a conceptual framework for formalizing emergent organization in nursing practice. J Nurs Manag. 2019; 27(1):4-9.

3. Myny D, Van Hecke A, De Bacquer D, Verhaeghe S, Gobert M, Defloor T, et al. Determining a set of measurable and relevant factors affecting nursing workload in the acute care hospital setting: a cross-sectional study. Int J Nurs Stud. 2012; 49(4):427-36.

4. Geerligs L, Rankin NM, Shepherd HL, Butow P. Hospital-based interventions: a systematic review of staff-reported barriers and facilitators to implementation processes. Implement Sci. 2018; 13(1):36.

5. Grimshaw J, Eccles M, Tetroe J. Implementing clinical guidelines: current evidence and future implications. J Contin Educ Health Prof. 2004; 24.

6. Rasmussen BSB, Jensen LK, Froekjaer J, Kidholm K, Kensing F, Yderstraede KB. A qualitative study of the key factors in implementing telemedical monitoring of diabetic foot ulcer patients. Int $\mathrm{J}$ Med Inform. 2015; 84(10):799-807.

7. McArthur C, Bai Y, Hewston P, Giangregorio L, Straus S, Papaioannou A. Barriers and facilitators to implementing evidence-based guidelines in long-term care: a qualitative evidence synthesis. Implement Sci. 2021;16(1):1-25. 
8. Beauchemin M, Cohn E, Shelton RC. Implementation of clinical practice guidelines in the healthcare setting: a concept analysis. ANS Adv Nurs Sci. 2019; 42(4):307-24.

9. Orr P, Davenport D. Embracing change. Nurs Clin North Am. 2015; 50(1):1-18.

10. Eccles MP, Armstrong D, Baker R, Cleary K, Davies H, Davies S, et al. An implementation research agenda. Implement Sci. 2009;4(1):18.

11. Proctor EK, Powell BJ, McMillen JC. Implementation strategies: recommendations for specifying and reporting. Implement Sci. 2013; 8:139.

12. Mitchell SA, Fisher CA, Hastings CE, Silverman LB, Wallen GR. A thematic analysis of theoretical models for translational science in nursing: mapping the field. Nurs Outlook. 2010; 58(6):287-300.

13. Nilsen P. Making sense of implementation theories, models and frameworks. Implement Sci. 2015;10:53.

14. Rycroft-Malone J. The PARIHS framework - a framework for guiding the implementation of evidencebased practice. J Nurs Care Qual. 2004;19(4):297-304.

15. Damschroder LJ, Aron DC, Keith RE, Kirsh SR, Alexander JA, Lowery JC. Fostering implementation of health services research findings into practice: a consolidated framework for advancing implementation science. Implement Sci. 2009; 4:50.

16. Allen D. Understanding context for quality improvement: artefacts, affordances and socio-material infrastructure. Health (London). 2013;17(5):460-77.

17. May CR, Johnson M, Finch T. Implementation, context and complexity. Implement Sci. 2016 19;11(1):141.

18. Waelli M, Gomez M-L, Sicotte C, Zicari A, Bonnefond J-Y, Lorino P, et al. Keys to successful implementation of a French national quality indicator in health care organizations: a qualitative study. BMC Health Serv Res. 2016; 16(1):553.

19. Andreasson J, Eriksson A, Dellve L. Health care managers' views on and approaches to implementing models for improving care processes. J Nurs Manag. 2016; 24(2):219-27.

20. Birken SA, Currie G. Using organization theory to position middle-level managers as agents of evidence-based practice implementation. Implement Sci. 2021;16(1):37.

21. Meza RD, Triplett NS, Woodard GS, Martin P, Khairuzzaman AN, Jamora G, et al. The relationship between first-level leadership and inner-context and implementation outcomes in behavioral health: a scoping review. Implement Sci. 2021;16(1):1-21.

22. González-María E, Moreno-Casbas MT, Albornos-Muñoz L, Grinspun D. The implementation of best practice guidelines in Spain through the program of the best practice spotlight organizations ${ }^{\circledR}$. Enfermería Clínica (English Edition). 2020; 30(3):136-44.

23. May C, Sibley A, Hunt K. The nursing work of hospital-based clinical practice guideline implementation: an explanatory systematic review using Normalisation Process Theory. Int J Nurs Stud. 2014; 51(2):289-99. 
24. Salma I, Waelli M. A framework for the implementation of certification procedures in nurse level: a mixed approach study. BMC Health Serv Res. 2021; 21:932.

25. Meyers DC, Durlak JA, Wandersman A. The quality implementation framework: a synthesis of critical steps in the implementation process. Am J Community Psychol. 2012; 50(3-4):462-80.

26. Allen D. Translational mobilization theory: a new paradigm for understanding the organizational elements of nursing work. Int J Nurs Stud. 2018;79:36-42.

27. Holcman R. Accréditation et certification [Accreditation and certification]. Guides Santé Social. 2015;2e ed.:269-92.

28. Duval AC. Ancrer le changement: un défi des soignants lors de la démarche de certification, une étude qualitative. Revue Francophone Internationale de Recherche Infirmière. 2017 ;3(3):181-8.

29. Hesselink G, Berben S, Beune T, Schoonhoven L. Improving the governance of patient safety in emergency care: a systematic review of interventions. BMJ Open. 2016;6(1):e009837.

30. Houghton C, Casey D, Shaw D, Murphy K. Rigor in qualitative case-study research. Nurse Res. 2013;20(4):12-7.

31. Crowe S, Cresswell K, Robertson A, Huby G, Avery A, Sheikh A. The case study approach. BMC Med Res Methodol. 2011;11:100.

32. Greene D, David JL. A research design for generalizing from multiple case studies. Eval and Program Plann. 1984;7(1):73-85.

33. Nyanchoka L, Tudur-Smith C, Porcher R, Hren D. Key stakeholders' perspectives and experiences with defining, identifying and displaying gaps in health research: a qualitative study protocol. BMJ Open. 2019; 9(8).

34. Moser A, Korstjens I. Series: Practical guidance to qualitative research. Part 3: sampling, data collection and analysis. Eur J Gen Pract. 2018; 24(1):9-18.

35. Guerrero EG, Padwa H, Fenwick K, Harris LM, Aarons GA. Identifying and ranking implicit leadership strategies to promote evidence-based practice implementation in addiction health services. Implement Sci. 2016;11:69.

36. Melo S, Bishop S. Translating healthcare research evidence into practice: the role of linked boundary objects. Soc Sci Med. 2020; 246:112731.

37. Tong A, Sainsbury P, Craig J. Consolidated criteria for reporting qualitative research (COREQ): a 32item checklist for interviews and focus groups. Int J Qual Health Care. 2007; 19(6):349-57.

38. Miech EJ, Rattray NA, Flanagan ME, Damschroder L, Schmid AA, Damush TM. Inside help: an integrative review of champions in healthcare-related implementation. SAGE Open Med. 2018;6:2050312118773261.

39. Dariel OP, Waelli M, Ricketts TC. France's transition to academic nursing: the theory-practice gap. J Nurs Educ Pract. 2014;4(10):88.

40. LOI n 2012-300 du 5 mars 2012 relative aux recherches impliquant la personne humaine [LAW No. $2012-300$ of 5 March 2012 relating to research involving the human person]. . 2016 
https://www.legifrance.gouv.fr/loda/id/JORFTEXT000025441587/. Accessed 20 Jun 2021.

41. DiCicco-Bloom B, Crabtree BF. The qualitative research interview. Med Educ. 2006;40(4):314-21.

42. Pettigrew A, Ferlie E, McKee L. Shaping strategic change - the case of the NHS in the 1980s. Public Money \& Management. 1992;12(3):27-31.

43. Dobbins M, Ciliska D, Cockerill R, Barnsley J, DiCenso A. A framework for the dissemination and utilization of research for health-care policy and practice. Online J Knowl Synth Nurs. 2002; 9:7.

44. Dryden-Palmer KD, Parshuram CS, Berta WB. Context, complexity and process in the implementation of evidence-based innovation: a realist informed review. BMC Health Serv Res. 2020;20:81.

45. Jansson I, Pilhamar E, Forsberg A. Factors and conditions that have an impact in relation to the successful implementation and maintenance of individual care plans. Worldviews Evid Based Nurs. 2011 Jun;8(2):66-75.

46. Barr BJ. Managing change during an information systems transition. AORN J. 2002;75(6):1085-92.

47. Wolak E, Overman A, Willis B, Hedges C, Spivak GF. Maximizing the benefit of quality improvement activities: a spread of innovations model. J Nurs Care Qual. 2020;35(3):199-205.

48. Jun J, Kovner CT, Stimpfel AW. Barriers and facilitators of nurses' use of clinical practice guidelines: an integrative review. Int J Nurs Stud. 2016;60:54-68.

49. Qin X, Yu P, Li H, Hu Y, Li X, Wang Q, et al. Integrating the "best" evidence into nursing of venous thromboembolism in ICU patients using the i-PARIHS framework. PLoS One. 2020;15(8).

50. Mettre en œuvre la certification pour la qualité des soins [Implementing certification procedure for care quality]. Haute Autorité de Santé. https://www.has-sante.fr/jcms/r_1495044/en/mettre-enoeuvre-la-certification-pour-la-qualite-des-soins. Accessed: 2021 Sep 29.

\section{Tables}

Table 1: Hospital characteristics

\begin{tabular}{|llll|}
\hline Hospitals & A & B & C \\
\hline Type & Teaching hospital & Hospital & Hospital \\
Size (beds) & 924 & 991 & 450 \\
Status & Public & Public & Private \\
Selected Sites & Medicine & Medicine & Medicine \\
& & Intensive care unit (ICU) & Palliative care \\
& & Endoscopy & Operating room \\
\hline
\end{tabular}




\begin{tabular}{|lcccc|}
\hline Hospital & A & B & C & TOTAL \\
\hline Top leader (TL) & 4 & 3 & 2 & 9 \\
\hline Mid-manager (MM) & 2 & 4 & 3 & 9 \\
\hline Registered nurse (RN) & 3 & 7 & 5 & 15 \\
\hline TOTAL & 9 & 14 & 10 & 33 \\
\hline
\end{tabular}

Table 3:Definitions of IFINP components based on the previous literature $[26,35,38]$

\begin{tabular}{|c|c|c|}
\hline & Elements & Definition \\
\hline \multirow{5}{*}{$\begin{array}{l}\text { Mobilization } \\
\text { mechanisms } \\
-[26]\end{array}$} & $\begin{array}{l}\text { Object } \\
\text { formation }\end{array}$ & $\begin{array}{l}\text { "practices that create the objects of knowledge and practice and } \\
\text { enrol them into a project" }\end{array}$ \\
\hline & Translation & $\begin{array}{l}\text { "practices that enable practice objects to be shared, and differing } \\
\text { viewpoints, local contingencies, and multiple interests } \\
\text { accommodated to enable concerted action" }\end{array}$ \\
\hline & Sense-making & $\begin{array}{l}\text { "practices though which actors interpret, order, construct, and } \\
\text { account for projects, and at the same time, produce and } \\
\text { reproduce institutions" }\end{array}$ \\
\hline & $\begin{array}{l}\text { Reflexive } \\
\text { monitoring }\end{array}$ & $\begin{array}{l}\text { "practices through which actors evaluate a field of action to } \\
\text { generate situational awareness of project trajectories" }\end{array}$ \\
\hline & $\begin{array}{l}\text { Work } \\
\text { articulation }\end{array}$ & $\begin{array}{l}\text { "practices that assemble and align elements (people, knowledge, } \\
\text { materials, technologies, and bodies) through which object } \\
\text { trajectories are mobilized within projects" }\end{array}$ \\
\hline \multirow[t]{6}{*}{$\begin{array}{l}\text { Contextual } \\
\text { elements }\end{array}$} & $\begin{array}{l}\text { Organizational } \\
\text { logics }\end{array}$ & $\begin{array}{l}\text { "elements which provide a set of normative conventions that } \\
\text { define the scope of possible action, and shape its purpose" [26] }\end{array}$ \\
\hline & Structure & $\begin{array}{l}\text { "elements that stratify social relations, e.g., social roles, division } \\
\text { of labor, professions, hierarchies, departments, units, and teams" } \\
{[26]}\end{array}$ \\
\hline & $\begin{array}{l}\text { Materials and } \\
\text { technologies }\end{array}$ & $\begin{array}{l}\text { "elements that provide agents with the physical artefacts to } \\
\text { support their practice, e.g., tools, technologies, bodies, and } \\
\text { knowledge" [26] }\end{array}$ \\
\hline & $\begin{array}{l}\text { Interpretative } \\
\text { repertoire }\end{array}$ & $\begin{array}{l}\text { "elements that provide agents with the cognitive artefacts for } \\
\text { sense making or for example, classifications, scripts, categories, } \\
\text { discourses, and routines" [26] }\end{array}$ \\
\hline & $\begin{array}{l}\text { Implementation } \\
\text { leadership }\end{array}$ & $\begin{array}{l}\text { "strategic approaches characterized by influencing behaviors to } \\
\text { promote success in implementation" [35] }\end{array}$ \\
\hline & $\begin{array}{l}\text { Champions/ } \\
\text { referent }\end{array}$ & $\begin{array}{l}\text { 'Key actors may emerge during an implementation process, } \\
\text { sometimes as part of an intervention, sometimes as part of an } \\
\text { implementation strategy, and at times, neither' [38] }\end{array}$ \\
\hline
\end{tabular}


Table 4: Analysis of the three studied context using the IFINP components. 


\begin{tabular}{|llll|}
\hline Elements & A & B \\
\hline $\begin{array}{l}\text { Mechanisms } \\
\text { of } \\
\text { Mobilization }\end{array}$ & $\begin{array}{l}\text { Object } \\
\text { formation }\end{array}$ & $\begin{array}{l}\text { 'often it is our } \\
\text { manager that } \\
\text { alerts us to a } \\
\text { change in } \\
\text { protocol' RN2 }\end{array}$ & $\begin{array}{l}\text { 'We prepare our } \\
\text { action map } \\
\text { according to } \\
\text { certification } \\
\text { requirements. Also, }\end{array}$ \\
& & $\begin{array}{l}\text { all the identified risks } \\
\text { are objectified and }\end{array}$ \\
& & we define our \\
& & corrective actions. \\
& & These are integrated \\
& & into our quality care \\
& & action plan' TL1
\end{tabular}

C

'We put the new document on the online document management system, in order to be accessible for all professionals. We diffuse an information that it is implemented. Then each local manager is responsible to diffuse the information to their teams and implement the document' TL2

$\begin{array}{lll}\text { Translation } & \begin{array}{l}\text { 'As a local } \\ \text { manager we are }\end{array} & \begin{array}{l}\text { 'we have to explain } \\ \text { fogularly nurses that, what }\end{array} \\ \text { clarify the interest } & \text { they are doing in } \\ \text { of new procedure of certification } & \text { procedures is } \\ \text { to professionals, } & \text { beneficial for patient } \\ \text { why we do it, for } & \text { care and to improve } \\ \text { what purpose. It } & \text { their work, even if it is } \\ \text { is not because we } & \text { perceived as } \\ \text { write or adapt the } & \text { additional } \\ \text { procedure to } & \text { traceability or work' } \\ \text { service it will be } & \text { MM1 } \\ \text { implemented!' } & \\ \text { MM2 } & \end{array}$

'we have to clarify that the new procedure has an interest for them and for the patient, they must find a benefit which will help change their habits a little' MM2

Sense-making
'Nurse are involved in the implementation process. In fact, I can't do it alone, because I don't know all about their daily difficulties. I think they will be much more precise in the finesse of things, that it is why they must be engaged' MM1
'The fact that we are not directly imposing a solution but involving them (nurses) in the debate during the preparations for implementation, is major facilitator to integrate changes into their routine, I think' MM2
'In fact to write a procedure with professionals can guarantees a better appropriation. For example, bring them to reflect on their practice and work with us on the improvement possibilities gives sense to their practices' TL2

\section{Reflexive monitoring}

'For a new protocol we have to adapt it and use it. Once we get used to it, we evaluate after that we readjust, 'at times we will have some lack, one of things that we are going to implement do not necessarily fully integrated. The feedback of services 'we have to report a malfunction in terms of the implemented changes, and also questioning the quality department, 
readapt and

reevaluate what is

blocking or the

things that are

not coherent' RN1 will alert us on

problem. And sharing

professional

experience and

feedback to enrich

services on others

previous experience,

so that they do not

relive the same

problem' TL2

\section{Work articulation}

Contextual elements 'sometimes we

have to go to

training to learn

gestures or

understand why

we make a

gesture in such

and such a way,

here we discuss

between us about

the new change

and also we

exchange

information' RN2 'every week there is a staff meeting in which we explain, observe, evaluate and analyze, so that teams can appropriate more' MM1 so this

implemented changer can be readjusted' RN1 'the quality department analyzes and then following the degree of feedback, we can organize a meetings to point out the concerns that we encounter to adjust' RN1
'I think it's a culture, the Culture of improving care facilitates the implementation of certification procedures' MM1 'we have to boost the culture of the quality approach between professional, which is quality and risk management culture' TL1

$\begin{array}{ll}\text { Structure } & \text { 'We are supported } \\ \text { by the quality unit } \\ \text { for the } \\ \text { implementation } \\ \text { of quality } \\ \text { policies. The unit } \\ \text { defines the } \\ \text { working plan at } \\ \text { different } \\ \text { levels' MM2 }\end{array}$

'we have to create a steering committees with all the departments, all the wards heads, the pole managers to be able to discuss all the themes in order to start organization' , TL2 'there is members

of the

management committee or wards executives, thematic referents, different bodies the CLIN* the CLUD*, we have professionals who can be nurses or other professionals' TL2

\section{Materials and technologies}

'first, we must

have the

materials in our

disposal, which is

it necessary to implement a new procedure' RN2
'We conduct always an analysis of the situation, we review we have and potential resources that we can have, and also we work with the concerned people' MM2
'Usually the procedure is created, often it is by a higher level it means the direction. we have our informatics system in which all our protocols 
are grouped

together' RN5

\section{Interpretative repertoire}

'For example we have a protocol

file in the department, in which is identified how to conduct a such and such care, it means the working process of care that should be followed' RN2
'We already have tools supporting the implemented changes. For example on the computer there is a folder for the recent information, we also have an information file. I use these sometimes for certain protocols' RN1
'We have an administrative support for our protocol, and we know that we can refer for information in there. I think, this, helps a lot, not only to go have all the information supporting our practice but also to be up to date' RN5

\section{Implementation leadership}

'The proximity manager it has a central role in the appropriation of caregivers to change, by their functioning mode.. as proximity manager, I think I am really in the loop, we go within the teams and we identify main elements and barriers, and we try to find solutions' MM1

\section{Champions}

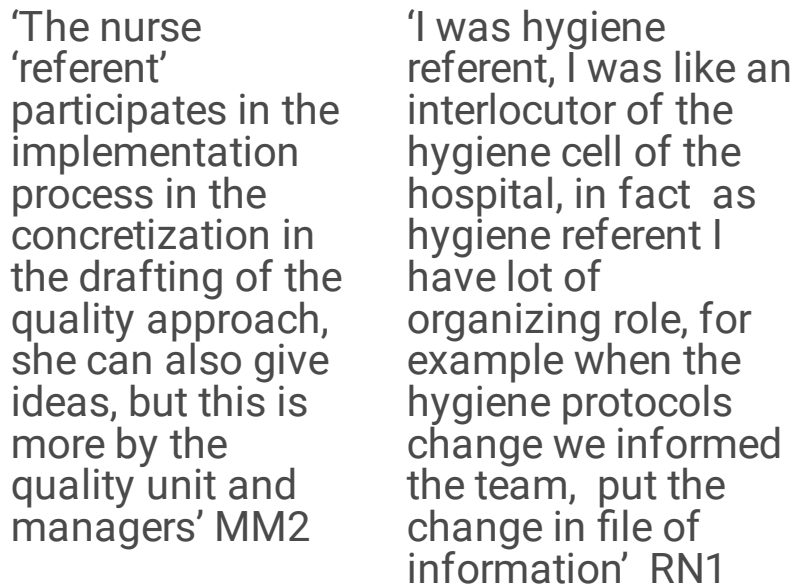

'We support them
(nurses) on their
knowledge and
competence, their
own current resource,
In fact we listen to
their need for
supervision, and
support then on their
own practice' MM2

'I am there in pilot of certification. I actually organize the dispatching of certification themes of different actors, and I ensure the proper follow-up and the good timing with the other pilots in charge of the in implementation at the activity level' TL2

'but all nurses are
concerned in the
implementation of
certification
procedure, however
you have motor
nurses who are
generally the
specialist referents
and then others
who follow more or
less voluntarily'
TL1

'but all nurses are concerned in the implementation of certification procedure, however you have motor nurses who are generally the specialist referents who follow more less voluntarily' TL1

${ }^{*}$ CLIN: nosocomial infection control committee; * CLUD: committee for pain relief and control 
Table 5: Site (A, B, and C) comparisons of object formation and translation mechanisms and interference with the leadership

\begin{tabular}{|c|c|c|c|}
\hline Mechanisms & A & B & C \\
\hline $\begin{array}{l}\text { Object } \\
\text { formation }\end{array}$ & $\begin{array}{l}\text { 'Usually, there are } \\
\text { referents for these } \\
\text { protocols. The hygiene } \\
\text { referent provides } \\
\text { information, or } \\
\text { information could come } \\
\text { from our local manager, } \\
\text { either directly or during } \\
\text { team meetings'. RN1 } \\
\text { (leadership) }\end{array}$ & $\begin{array}{l}\text { 'In thematic working } \\
\text { groups, we identified } \\
\text { what needed to be } \\
\text { formalized to introduce } \\
\text { and support procedures } \\
\text { in sectors, and what } \\
\text { was missing in sectors. } \\
\text { We also defined an } \\
\text { action plan'. TL2 }\end{array}$ & $\begin{array}{l}\text { 'Based on certification } \\
\text { criteria, we conducted } \\
\text { evaluations. For example, an } \\
\text { assessment is ongoing and } \\
\text { based on certification } \\
\text { requirements, or new criteria } \\
\text { will be defined and our } \\
\text { action plan formulated } \\
\text { accordingly'. TL2 }\end{array}$ \\
\hline \multirow[t]{2}{*}{ Translation } & $\begin{array}{l}\text { 'We are supported by the } \\
\text { quality unit for the } \\
\text { implementation of } \\
\text { quality policies. The unit } \\
\text { defines the working plan } \\
\text { at different levels'. MM2 } \\
\text { (leadership) }\end{array}$ & $\begin{array}{l}\text { 'The implemented } \\
\text { change must be } \\
\text { explained, why it is } \\
\text { needed, how it meets } \\
\text { patient care, and how it } \\
\text { works in our practice'. } \\
\text { RN2 }\end{array}$ & $\begin{array}{l}\text { 'Meetings help us explain } \\
\text { the benefits of these } \\
\text { procedures; we must remind } \\
\text { and communicate these } \\
\text { with our } \\
\text { colleagues'. TL1 (leadership) }\end{array}$ \\
\hline & $\begin{array}{l}\text { 'We explain to } \\
\text { professionals that } \\
\text { implemented procedures } \\
\text { improve patient care } \\
\text { quality and depend on } \\
\text { the shared culture of } \\
\text { quality and safety'. MM1 } \\
\text { (leadership) }\end{array}$ & $\begin{array}{l}\text { 'For nurses, certification } \\
\text { is distant from patient } \\
\text { care. So we } \\
\text { communicate key } \\
\text { information to clarify } \\
\text { ambiguous acronyms'. } \\
\text { MM3 (leadership) }\end{array}$ & $\begin{array}{l}\text { 'Certification implementation } \\
\text { procedures often require } \\
\text { translation for } \\
\text { professionals. This is a } \\
\text { major difficulty every time; I } \\
\text { must translate these } \\
\text { procedures with respect to } \\
\text { their professional practice'. } \\
\text { TL2 (leadership) }\end{array}$ \\
\hline
\end{tabular}

Table 6: Site (A, B and C) comparisons for sense-making, reflexive monitoring, and work articulation mechanisms with the leadership 


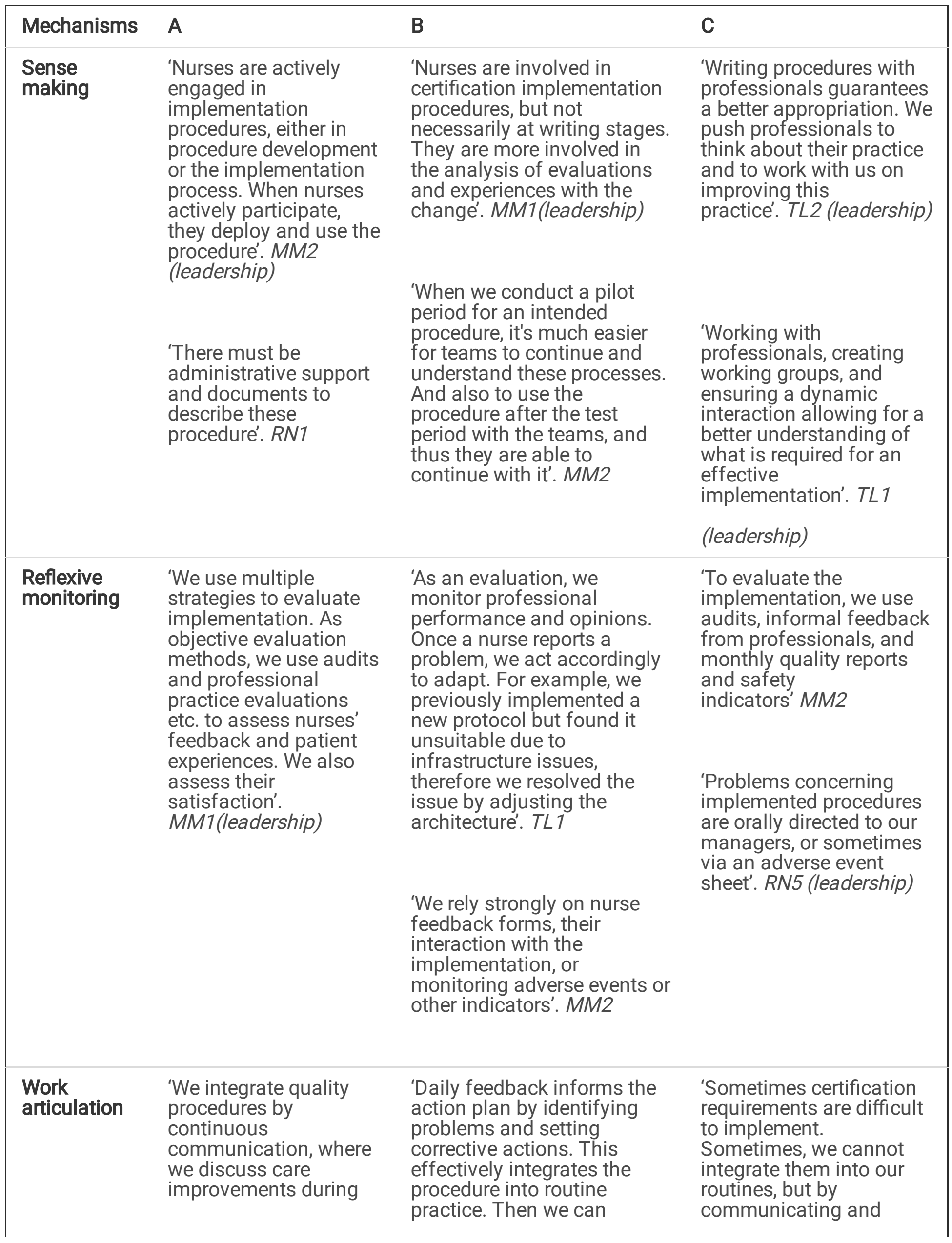

Page 22/ 24 
pursue new objectives to improve patient care'. MM2 (leadership) exchanging ideas with managers, we evolve and improve these requirements'. $R N 4$

\section{Figures}

\section{Certification procedure}

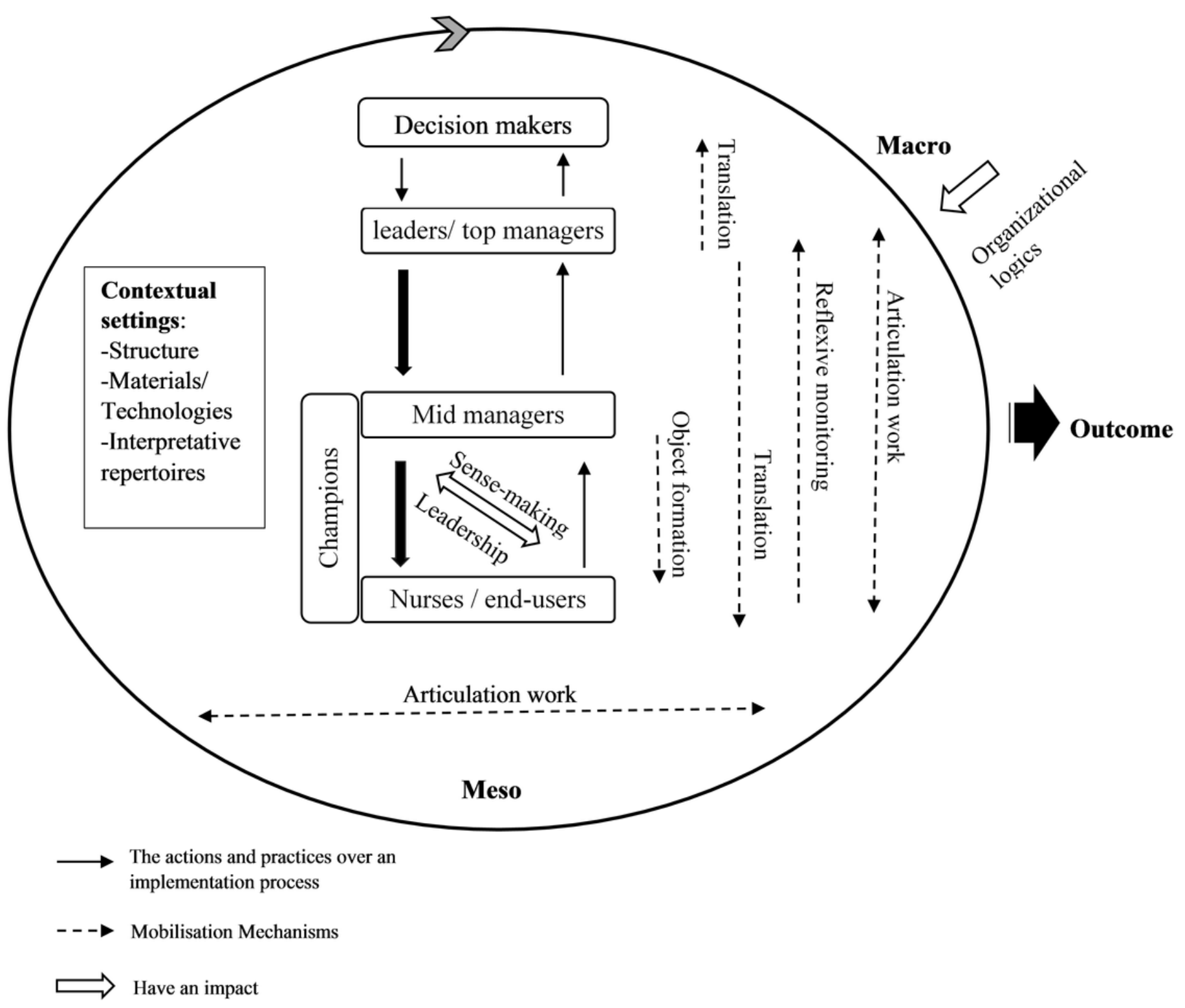

Figure 1

The Integrative Framework for Implementation of change in Nursing Practices (IFINP). IFINP facilitates the implementation of innovation into practice. It identifies different macro and meso levels during an implementation process. Macro levels reflect healthcare systems. Meso levels reflect organizational levels which consist of contextual settings and actors involved in certificate implementation processes at 
different organizational levels. Mobilization mechanisms also include object formation, translation, work articulation, reflexive monitoring, and sense-making. These shape interrelationships between framework components. IFINP also identifies the leadership approach of change leaders at local levels (champions and/or local managers) [24].

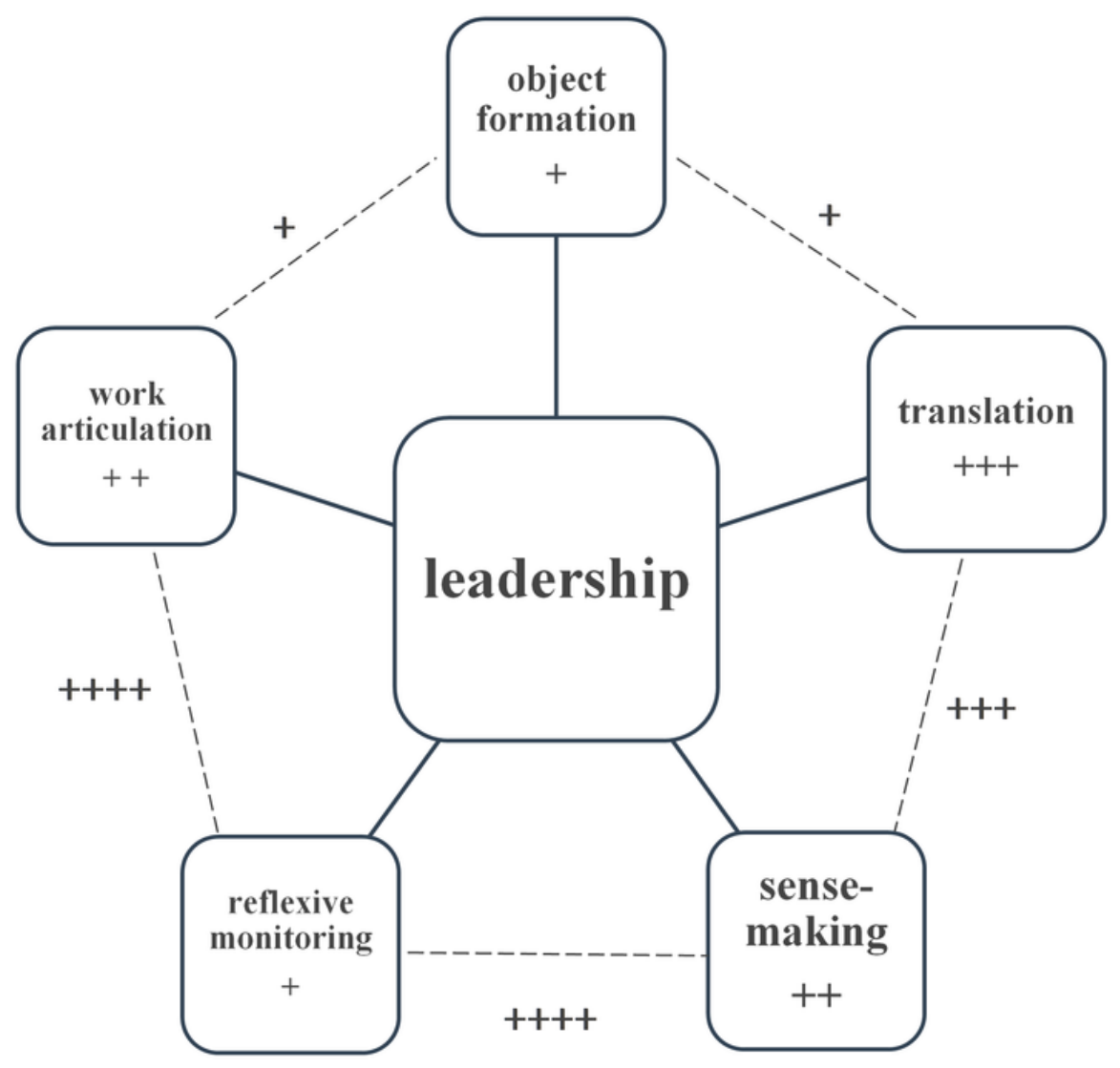

- - _ : Intra-interference of mobilization mechanisms

: Inter- inference of leadership and the mechanisms

+: The interference level

\section{Figure 2}

General representation of interference on mobilization mechanisms and leadership elements. The + signs represent interference levels and dashed lines represent intra-interference mechanisms. Full lines represent the inter-interference of leadership and mechanisms.

\section{Supplementary Files}

This is a list of supplementary files associated with this preprint. Click to download.

- additionalfile1.docx

- additionalfile2.docx 